\title{
The Effect of Fe Addition on Fragmentation Phenomena, Macrostructure, Microstructure, and Hardness of TiC-Fe Local Reinforcements Fabricated In Situ in Steel Casting
}

\author{
EWA OLEJNIK, TOMASZ TOKARSKI, GABRIELA SIKORA, SEBASTIAN SOBULA, \\ WOJCIECH MAZIARZ, ŁUKASZ SZYMAŃSKI, and BEATA GRABOWSKA
}

\begin{abstract}
The dependences of the macro- and microstructures as well as the hardness of local TiC-Fe-type reinforcements (LR) fabricated in situ in steel casting using compacts containing different contents of $\mathrm{TiC}$ reactants and the addition of an $\mathrm{Fe}$ moderator have been investigated using scanning electron microscopy (SEM), transmission electron microscopy (TEM), X-ray diffraction (XRD), and Vickers hardness (HV) tests. Five powder mixtures were selected for compact preparation; one of them contains only $\mathrm{TiC}$ reactants, while the other four contain $\mathrm{TiC}$ reactants as well as 10,30,50, and 70 wt pet Fe moderator additions, respectively. Next, the ready compacts were introduced to the mold cavity and poured by cast steel for the in situ LR fabrication. This is the first time, through this study, that the fragmentation phenomena was revealed by macrostructural observations of the LR produced with only the TiC reactants. The increasing $\mathrm{Fe}$ content gradually limited the fragmentation and infiltration processes and stabilized the dimensions of the LR. With the increasing contents of the Fe moderator, the refinement of the $\mathrm{TiC}$ particles in the LR was observed. Due to the limited infiltration process and high surface content of the TiC, the LR produced with 30 wt pct Fe exhibited the greatest hardness.
\end{abstract}

https://doi.org/10.1007/s11661-018-4992-6

(C) The Author(s) 2018

\section{INTRODUCTION}

ABRASIVE wear is one of the main factors that eliminates thousands of tons of the casting parts of machines and devices annually in large market-related industries such as mining, aggregate, and cement. Designing and manufacturing of in situ locally reinforced castings (LRCs) creates opportunities for marked increases in their service lives. There are two different routes for achieving in situ local reinforcement (LR) in

EWA OLEJNIK, GABRIELA SIKORA, SEBASTIAN SOBULA, and LUKASZ SZYMAŃSKI are with the Department of Engineering of Cast Alloys and Composites, Faculty of Foundry Engineering, AGH University of Science and Technology, Reymonta 23 St., 30-059 Krakow. Contact e-mail: eolejnik@agh.edu.pl TOMASZ TOKARSKI is with the Academic Center for Materials and Nanotechnology, AGH University of Science and Technology, Mickiewicza 30 Av., 30-059 Krakow, Poland. WOJCIECH MAZIARZ is with the Polish Academy of Sciences, Institute of Metallurgy and Materials Science, Reymonta 25 St., 30-059 Krakow, Poland. BEATA GRABOWSKA is with the Department of Foundry Processes Engineering, Faculty of Foundry Engineering, AGH University of Science and Technology, Reymonta 23 St., 30-059 Krakow, Poland.

Manuscript submitted June 26, 2018.

Article published online November 27, 2018 casting that have been explored in the literature. Both routes based on the use of the well-known self-propagating high-temperature synthesis (SHS) reaction, ${ }^{[1-3]}$ which allows us to obtain carbides, borides, and nitrides directly from alloys. ${ }^{[4]}$ The first way involves placing one reactant of a selected type of carbide in the form of a vanadium plate ${ }^{[5]}$ or tungsten wire ${ }^{[6]}$ into the mold cavity, while the second reactant is introduced as a component liquid alloy poured into the mold cavity. The molten alloy activates the reaction between the reactants introduced into the mold, and reinforcement particles such as vanadium carbide $(\mathrm{VC})^{[5]}$ and tungsten carbide $(\mathrm{WC})^{[6,7]}$ are formed directly in the casting. Zhong et al ${ }^{[8]}$ reported a method of producing WC reinforcement on the surface of an iron matrix based on a $\mathrm{W}$ plate introduced into a mold cavity, which is then filled by a liquid alloy. The composite's surface is formed with solid-phase diffusion during the heat treatment of the ready casting part. The advantage of this method is a uniform and dimensionally stable layer reinforced by an 80 pct volume fraction of WC particles. Some limitations of this method are the long heat-treatment time and relatively small layer thickness (which is $148 \mu \mathrm{m}$ after 8 hours of annealing at a temperature of $1423 \mathrm{~K}$ ). The essence of the second method is the placement of green compacts containing mixtures of 
$\mathrm{TiC}$ or $\mathrm{TiC}$ and $\mathrm{TiB}_{2}$ reactants undergoing the SHS reaction ${ }^{[9-21]}$ in a mold cavity. ${ }^{[5-15]}$ Similar to the previous method, the liquid alloy poured into the mold cavity activates the SHS reactions, but due to the self-sustaining reaction occurring in the whole compact, it is possible to fabricate an LR in a wide range of dimensions. This means that this method is particularly attractive for the local reinforcement of castings. In this case, it is not necessary to perform additional heat treatments of the casting.

According to the results reported in several studies, it is possible to fabricate LR in situ in a casting using green compacts containing $\mathrm{VC}, \mathrm{TiC}$, or $\mathrm{TiC}$ and $\mathrm{TiB}_{2}$ reactants as well as additions such as $\mathrm{Cu}, \mathrm{Al}, \mathrm{Ni}$, and $\mathrm{Fe}$. Unfortunately, most of the published papers ${ }^{[9-24]}$ do neither contain the visualization nor discussion about the macrostructure of the LRC, which is key for assessing the dimensional stability and potential defects of the LRC. The LRC microstructure has a predominant influence on the mechanical and service properties of the cast parts and should not be ignored.

Based on the available knowledge, we can certainly fabricate an LRC in situ in the castings with the above-mentioned method. Meanwhile, a comprehensive macrostructure study of the LRC carried out as part of this study sheds new light on this subject.

The fundamental problem identified in this study is related to the inability of controlling the SHS TiC reaction during the in situ fabrication of the LRC in the steel casting. The reaction of TiC synthesis is highly exothermic, ${ }^{[25]}$ with the enthalpy of $-187 \mathrm{~kJ} / \mathrm{mol}$. Intensive energy production in a form of generated heat results in the local increase of temperature of liquid metal, significantly intensifying the phenomenon of infiltration ${ }^{[26-29]}$ within local composite reinforcement. Thus, TiCs are being separated by liquid metal casting alloy; due to lower density, they move within casting. This phenomenon is called composite zone fragmentation. ${ }^{\text {[30] }}$

To show and solve the above-mentioned fragmentation problem, studies were undertaken to examine the macrostructure, microstructure, and hardness of the TiC-reinforced LRCs fabricated in situ in the steel casting without and with the addition of $\mathrm{Fe}$. The fragmentation of the LRC phenomena in casting without and with a small content of the Fe addition is presented and discussed in this paper. The optimal content of the $\mathrm{Fe}$ addition was found for which a dimensionally stable LRC was obtained in the steel castings. The current study revealed that, due to the limited infiltration process and relatively high surface content of $\mathrm{TiC}$, the LRC produced with 30 wt pet $\mathrm{Fe}$ exhibited the greatest hardness.

\section{EXPERIMENTAL}

Reactants for the in situ formation of $\mathrm{TiC}$ were prepared using $\mathrm{Ti}$ powders of an average diameter of $44 \mu \mathrm{m}$ and purity of $99.8 \mathrm{pct}$ as well as graphite of an average diameter of $44 \mu \mathrm{m}$ and purity of 99.9 pct while maintaining a mutual atomic fraction of $\mathrm{Ti}$ to $\mathrm{C}$ equal to 1:1. The moderator was prepared from Fe powder of an average diameter of $44 \mu \mathrm{m}$ and purity of 99.8 pct. Five powder mixtures ware selected for the compact preparation; one of them containing only $\mathrm{TiC}$ reactants, while the other four contained $\mathrm{TiC}$ reactants and 10, 30, 50, and $70 \mathrm{wt}$ pct Fe moderator additions, respectively. The weight fraction of the $\mathrm{TiC}$ reactants and moderator used for the preparation of the compacts is included in Table I. In order to additionally examine the effect of the Fe moderator on the microhardness, microstructure, and hardness, one graded compact with five layers was prepared. Each of the powder layers of the graded compact had the same chemical composition as the compacts with symbols A to E (see Table I). The individual layers were arranged parallel to the longer side of the compact.

Table II demonstrates the results of relative density determined for compositions A to $\mathrm{E}$ which are presented in Table I. Compactibility of powder is defined as susceptibility to compacting under pressure. As the measure of this value, we have taken the quotient of the density of compact to the applied pressure of cold work, which assures obtaining 65pct of theoretical density.

Each of the individual powder compositions (A to $\mathrm{E}$-indicated in Table I) were mixed for 6 hours in closed containers in shaker mixers (Turbula, Glen Mills, USA). Next, using a uniaxial press, the mixtures were

Table II. Relative Density of Green Compacts

\begin{tabular}{lcccccc}
\hline & \multicolumn{5}{c}{ Relative Density [Percent] } \\
\cline { 2 - 7 } Pressure [MPa] & A & B & C & D & E & F \\
\hline 500 & 72.94 & 71.34 & 69.33 & 67.30 & 74.49 & - \\
\hline
\end{tabular}

Table I. Weight Fraction of TiC Reactants and Fe Moderator in Green Compacts

\begin{tabular}{|c|c|c|c|c|c|c|}
\hline $\begin{array}{l}\text { Compact } \\
\text { Symbol }\end{array}$ & and & LRC & $\begin{array}{c}\text { Reactants of TiC, Weight } \\
\text { Percent }\end{array}$ & $\begin{array}{l}\text { Ti, Weight } \\
\text { Percent }\end{array}$ & $\begin{array}{l}\text { C, Weight } \\
\text { Percent }\end{array}$ & $\begin{array}{l}\text { Moderator, Weight } \\
\text { Percent }\end{array}$ \\
\hline $\bar{A}$ & & & 100 & 79.94 & 20.06 & 0 \\
\hline B & & & 90 & 71.94 & 18.06 & 10 \\
\hline $\mathrm{C}$ & & & 70 & 55.96 & 14.04 & 30 \\
\hline $\mathrm{D}$ & & & 50 & 39.97 & 10.03 & 50 \\
\hline $\mathrm{E}$ & & & 30 & 23.98 & 6.02 & 70 \\
\hline $\mathrm{F}$ & & & graded LRC & - & - & graded LRC \\
\hline
\end{tabular}




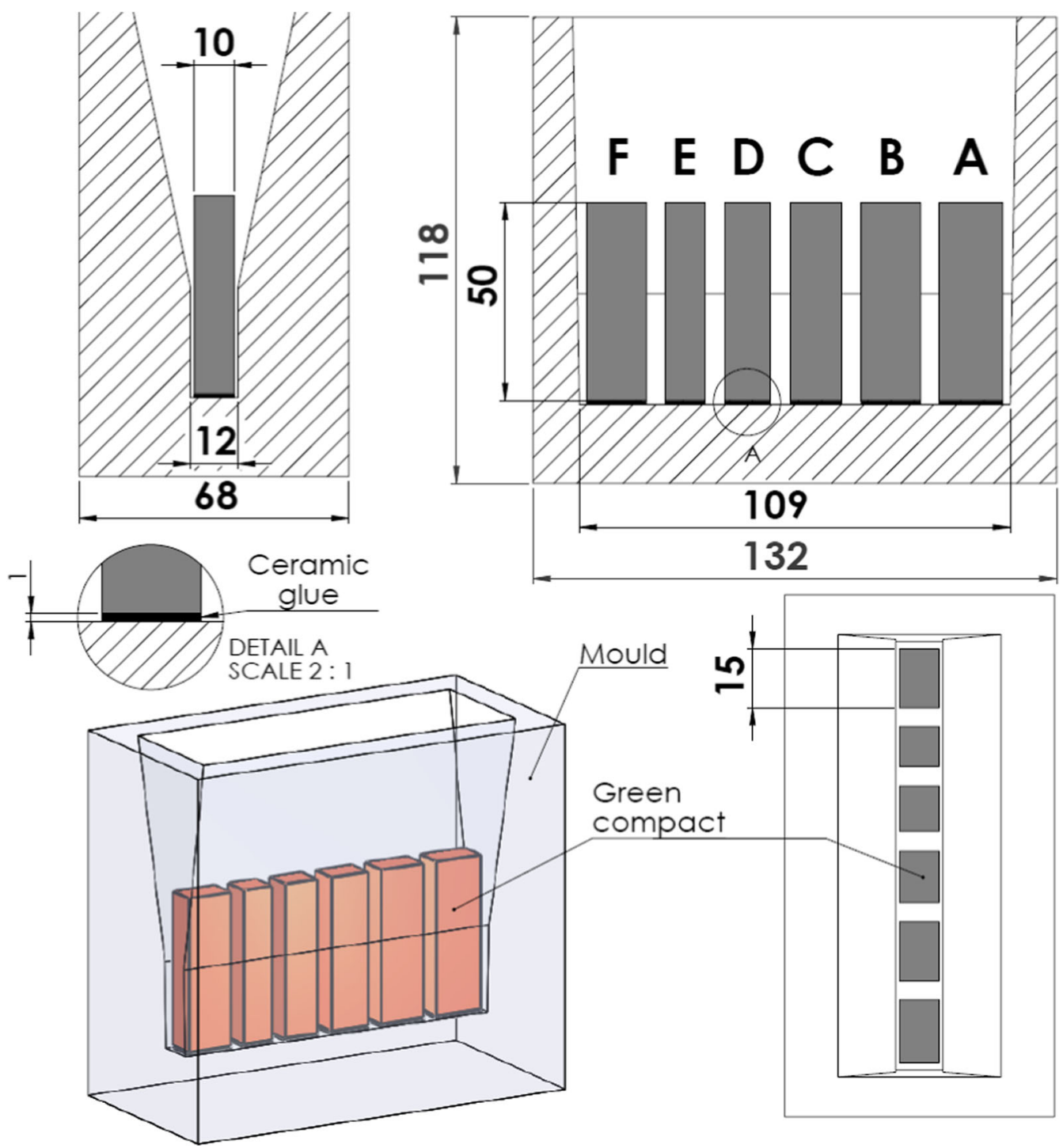

Fig. 1-Scheme of mold with compacts for in situ fabrication of LRC.

cold pressed under a pressure of $500 \mathrm{MPa}$. The compact with the abrupt gradient of the chemical composition ( $\mathrm{F}$-indicated in Table I) was obtained by charging individual mixtures of the powders to the die. After introducing all five layers into the matrix chamber, the powders were pressed under a pressure of $500 \mathrm{MPa}$. The obtained compacts, whose dimensions were $10 \times 50 \times \mathrm{Y}$ $\mathrm{mm}$ (where $\mathrm{Y}=$ the dimension as a result of the compactibility of the individual mixtures), were glued to the bottom of the mold cavity using ceramic glue (as shown in Figure 1).

Table III shows the results of measurements taken in order to define width of compacts placed in the mold cavity specified above as the dimension $\mathrm{Y}$. The obtained discrepancies of parameter $\mathrm{Y}$ stem from different compactibility of powder mixtures.

The mold was prepared using molochite powder and water glass and then hardened by $\mathrm{CO}_{2}$ blowing. A melted alloy, whose chemical composition is given in
Table III. Tabulation of Width of Green CompactsDimension Y

\begin{tabular}{lcccccc}
\hline Compact & A & B & C & D & E & F \\
\hline $\mathrm{Y}[\mathrm{mm}]$ & 15.8 & 14.3 & 12.7 & 11.3 & 9.8 & 12.8 \\
\hline
\end{tabular}

Table IV, was poured into the mold containing the compacts. The pouring temperature was $1770 \mathrm{~K}$.

The LRC obtained in situ in the steel castings was investigated by analyzing their macro- and microstructures as well as their hardness. The macrostructure of the LRC was observed by polishing sections of the casting. The dashed line in Figure 2 indicates the places from which the samples were cut. The microstructure of each of the individual A, B, C, D, E and graded F LRs was examined by means of electron scanning microscopy (SEM) with a backscattered electron (BSE) detector (Versa 3D, FEI). The microstructure and chemical composition of composite zone A were 
examined using Tecnai G2 Transmission Electron Microscope (TEM) equipped with energy dispersive X-ray microanalyzer (EDX) and High Angle Annular Dark Field (HAADF) detector. Thin foil samples for TEM observations were prepared by means of Focus Ion Beam (FIB). The diameters of the TiC particles were determined using the Olympus Basic Stream software. Surface fraction of reinforcement phase in "Image J" program is specified on the basis of differences in contrast between phases which can be found in the microstructure and which are automatically determined by the software. For this purpose, ten images of randomly selected areas of the microstructure for each LRC were analyzed. The diameter of the $\mathrm{TiC}$ particle was not determined for Composite Zone A (produced without the addition of a moderator) due to the high degree of coalescence. The phase composition of the LRC was verified by means of X-ray diffraction (Kristalloflex 4h, Siemens) by applying a radiation wavelength of $\mathrm{Cu}(\mathrm{K} \alpha=0.154 \mathrm{~nm})$. The hardness values of the LRC and the base alloy were measured using the Vickers method, applying a load of $298 \mathrm{~N}$ (HV30) for 10 seconds (Tukon 2500, Wilson-Hardness).

Table IV. Chemical Composition of Cast Steel

\begin{tabular}{lcccc}
\hline \multicolumn{5}{c}{ Chemical Composition, Weight Percent } \\
\hline $\mathrm{C}$ & $\mathrm{Si}$ & $\mathrm{Mn}$ & $\mathrm{P}$ & $\mathrm{S}$ \\
\hline 0.20 & 0.45 & 0.65 & 0.03 & 0.02 \\
\hline
\end{tabular}

\section{RESULTS AND DISCUSSION}

\section{A. Macrostructure of $L R C$}

Table $\mathrm{V}$ shows the results of the measurements of width for the in situ fabricated local composite reinforcements presented in Figure 2. This juxtaposition is meant to compare the initial compacts' size demonstrated in Table III with the size of local composite reinforcements. The obtained differences expressed in millimeters can be a basis to specify the infiltration degree which is defined as an increase in the percentage of composite reinforcements' width $\left(\mathrm{Y}_{\mathrm{LRC}}\right)$ compared with the size of the initial components $\left(\mathrm{Y}_{\mathrm{C}}\right)$. The analysis of the obtained results indicates that the difference between the compacts placed in the mold cavity and the in situ fabricated composite reinforcement decreases with the percentage of moderator consisting of pure iron powder.

Figure 2 shows the macrostructures of the individual and graded LRs produced in situ in the steel casting. In the case of LRC A (produced without the Fe moderator

Table V. Tabulation of Infiltration Degree of Composite Reinforcement

\begin{tabular}{lcccccc}
\multicolumn{7}{c}{ Reinforcement } \\
\hline Compact & A & B & C & D & E & F \\
\hline Y $_{\text {LCR }}[\mathrm{mm}]$ & 25 & 21 & 19 & 15 & 14 & 15 \\
Y $_{C}[\mathrm{~mm}]$ & 16 & 14 & 13 & 11 & 10 & 13 \\
Infiltration Degree [pct] & 36 & 33 & 31 & 26 & 28 & 13 \\
\hline
\end{tabular}
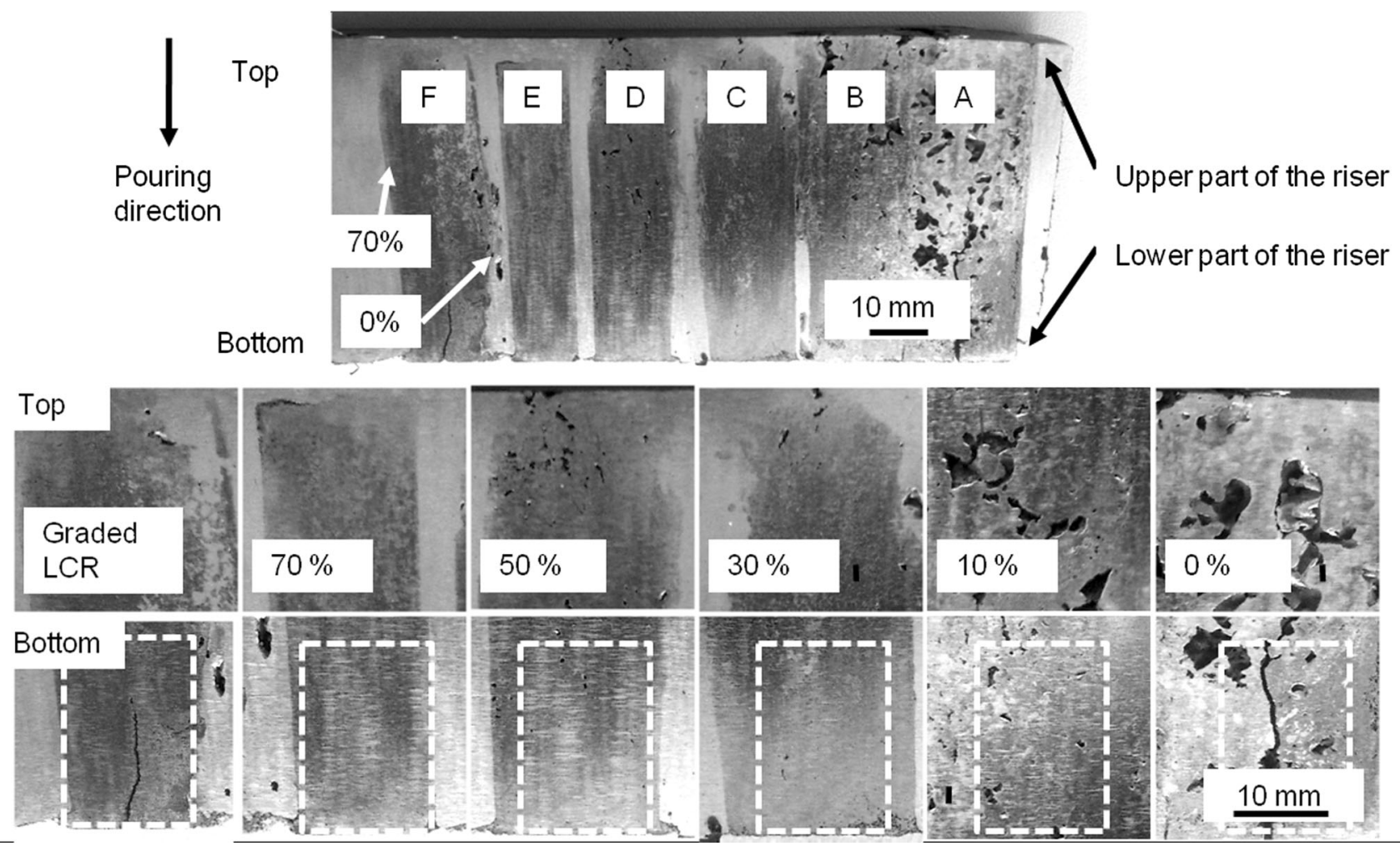

Fig. 2-Macrostructures of individual A, B, C, D, E, and graded F LRs obtained in situ in steel casting. 
addition), fragmentation, changes in the dimensions, and a significant fraction of macroporosity were revealed. These effects were caused by the temperature increase during the in situ $\mathrm{TiC}$ reaction, which favors the reactive infiltration process and gas emission. ${ }^{[31]}$ With the increasing amount of the Fe moderator, the tendency for the stabilization of the dimensions and a decrease in macroporosity content were visible within the LRC. The best dimensional stability and lowest content of gas holes were obtained in the case of LR E (fabricated with $70 \mathrm{wt}$ pct of the Fe moderator).

The graded LRC F formed in the casting (see Figure 2) had a diversified macrostructure, which was the result of the phenomena occurring in the individual layers of the compact introduced into the mold cavity. By analyzing its changes in the direction of decreasing amounts of the Fe addition, an increase in the degree of infiltration could be noticed. It manifested itself as fragmentation, blurred edges, and macroporosity within the area layer without the moderator.

A comparison of the lower and upper parts of the LRC fabricated in the casting (see Figure 2) indicated an increase in the infiltration degree within the riser head with a larger wall thickness, manifesting itself in the form of blurred edges (especially the upper parts of the zones). This caused a decrease in the $\mathrm{TiC}$ fraction within the zone in a similar fashion as in the case of Composite Zones A and B manufactured without and with a small $\mathrm{Fe}$ addition. The melt infiltrating the zones during the $\mathrm{TiC}$ exothermic synthesis reaction caused an increase in these zones' dimensions. An increase in the degree of infiltration in the upper parts of the LRC was caused by the fact that the riser head is last to solidify; as a consequence, the infiltration time and temperature were the highest in this area.

\section{B. Microstructure of $L R$}

Figure 3 shows the LR microstructures of the TiC-Fe/ $\mathrm{Fe}$ alloy $(\mathrm{TiC}$ - phase reinforcing, $\mathrm{Fe}$ - moderator, $\mathrm{Fe}$ alloy-base alloy, cast steel) type produced in situ in steel castings without (Figure 3(a)) and with the $\mathrm{Fe}$ moderator addition (Figures 3(b) through (e)). Composite Zone A (Figure 3(a)) was characterized by strongly coagulated $\mathrm{TiC}$ particles that formed the carbide skeleton. This skeleton was formed due to the coalescent effects of the TiC particles. LRC A contained large areas of coagulated $\mathrm{TiC}$ particles and large matrix areas in-between them. Composite Zone B (Figure 3(b)), obtained with the addition of 10 wt.pct of Fe, was characterized by a lower degree of coagulation of the TiC particles and their smaller average diameter $(4 \mu \mathrm{m})$ at the point of the distribution maximum (Figure 4(a)). In LR B, the microstructures of the individual $\mathrm{TiC}$ particles as well as the ones that underwent coalescence are seen. Between these TiC particles, the connections in the form of necks ${ }^{[32]}$ were visible. Composite Zone C (Figure 3(c)), fabricated with 30 wt.pct of the $\mathrm{Fe}$ moderator addition had large numbers of homogeneous transgranular TiC particles (contrary to LRs A and B). They had the bimodal size distribution of diameters 1.2 and $2.5 \mu \mathrm{m}$, respectively, in the first and second maximum of the distribution shown in Figure 4(b). The composite of Zone D (Figure 3(d)), obtained with $50 \mathrm{wt}$ pct of the Fe moderator, had a microstructure similar to Zone $\mathrm{C}$; however, the diameters of the particles were smaller (equaling 0.75 and $1.8 \mu \mathrm{m}$, respectively) for the first and second maximum of the bimodal distribution (Figure 4(c)). In the case of LR E (Figure 3(e)) produced with a 70 wt pct Fe addition, a further size decrease of the particles was observed. Their diameters for the first and second maximum of the bimodal distribution were equal to 0.7 and $1.6 \mu \mathrm{m}$, respectively (Figure 4(d)). Numerous gas microporosities were seen within composite Zone $\mathrm{E}$ (see inset in Figure 3(e)). The addition of the Fe moderator to the reactants of the $\mathrm{TiC}$ caused the increased porosity of the green compacts containing high contents of $\mathrm{Fe}$ powder. ${ }^{[24]}$

The observations of microstructure carried out by means of the scanning electron microscopy (SEM) showed new structural components, which cannot be found in the microstructure of the applied base alloy. Therefore, additional investigations were conducted by means of transmission electron microscopy (TEM) aimed the detailed identification of the phases observed. The investigations were carried out for the in situ fabricated composite reinforcement A. In the area selected for investigation of composite reinforcement matrix shown in Figure 5(a), three phases of ferrite $(\mathrm{Fe} \alpha), \mathrm{TiC}$, and $\mathrm{Fe}_{2} \mathrm{Ti}$ type were identified. The obtained results are compatible with ternary phase diagram $\mathrm{Fe}-\mathrm{C}-\mathrm{Ti}$ published in the literature. ${ }^{[33]}$ The chemical composition of the identified phases was initially confirmed by maps of elements distribution presented in Figure 5(b). The area of microstructure STEMHAADF selected for investigations was marked in Figure 5(a) with a gray square. The findings show mapping of element distribution in the transition area-between $\mathrm{TiC}$ ceramic phase and matrix of composite reinforcement, i.e., eutectic $\mathrm{Fe}_{2} \mathrm{Ti}+\mathrm{Fe} \alpha$.

In order to identify the chemical composition in the selected area of microstructure shown in Figure 5, three measuring points were marked for each of the identified phases obtained during $\mathrm{TiC}$ synthesis. The results are presented in the form of patterns and tabulated in Figure 6 . In the area marked as point 1 , mainly $\mathrm{Ti}$ and $\mathrm{C}$ were identified, which proves the presence of ceramic reinforcement phase in the form of TiC. Point 2 contains a considerable amount of $\mathrm{Fe}$, which is a dominant element of ferrite - a main structural component for the metal matrix applied i.d. base alloy. Point 3 was located in the area of eutectic which is a mixture of iron and titanium.

Figure 7 presents a set of bright field (BF) TEM and corresponding selected area diffraction pattern (SADP). SADPs are very well fitted to the cubic Fe $\alpha$, cubic TiC and hexagonal $\mathrm{Fe}_{2} \mathrm{Ti}$ phases with [111], [011] and [212] zone axes respectively.

The presented microstructure description makes it possible to discuss the phenomena that occur in the individual LRCs produced in situ in the casting while using variable amounts of the Fe moderator. First of all, a change in the morphology of the $\mathrm{TiC}$ carbide was seen 

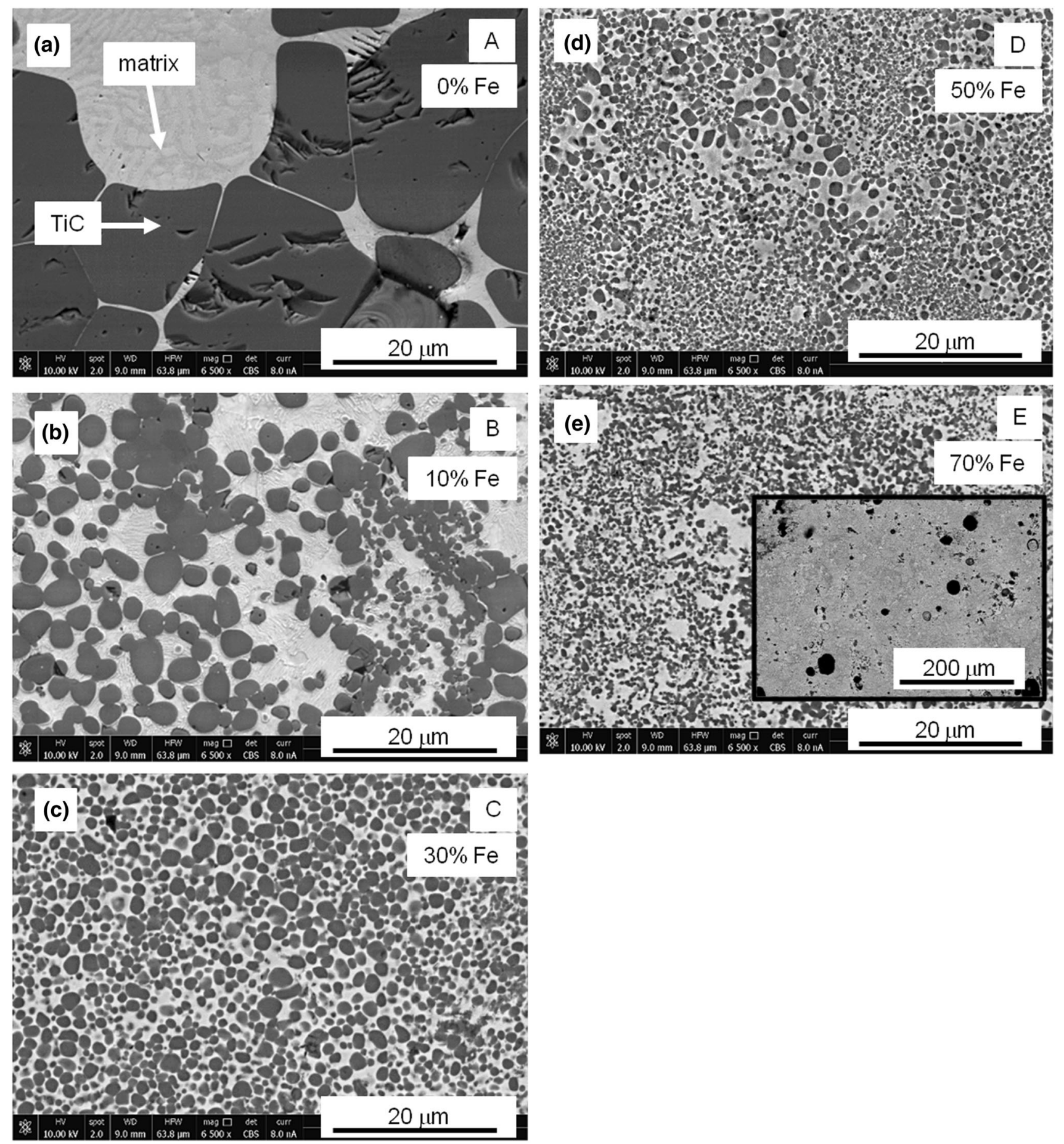

Fig. 3-SEM BSE microstructures of individual LRCs: A (a), B (b), C (c), D (d), and E (e) of TiC-Fe type fabricated in situ in steel casting.

in the microstructures of Zones $\mathrm{A}, \mathrm{B}, \mathrm{C}, \mathrm{D}$, and $\mathrm{E}$. Composite Zone A containing the highest concentration of TiC reactants is characterized by the compact structure of its coagulates. The energy dissipated during the exothermic reaction of the $\mathrm{TiC}$ synthesis increased its melting temperature, limiting the possibility of forming a large number of nuclei. In reality, only a small number of nuclei are formed due to the small degree of the supercooling of $\mathrm{TiC}$. The $\mathrm{TiC}$ particles growing in the liquid alloy were subjected to contact, neck growth, ${ }^{[34]}$ and coalescence, since an increased temperature favors the Brownian movements of particles ${ }^{[35]}$ increasing their probability of collisions (during which the TiC particles can attract each other). ${ }^{[36]}$ The transfer of reactants to the solid-liquid interface of these particles is intensified by the melt's high temperature since the atom mobility is increased. The coarse solid-liquid interface facilitates atom attachments since 


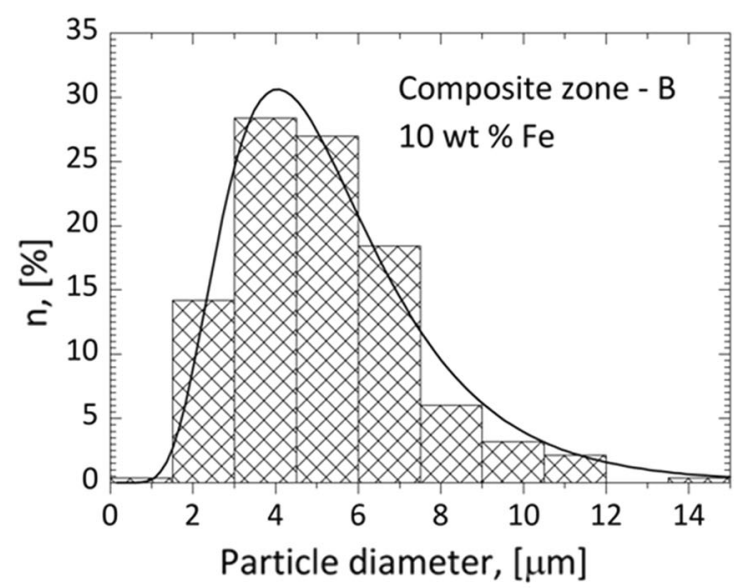

(a)

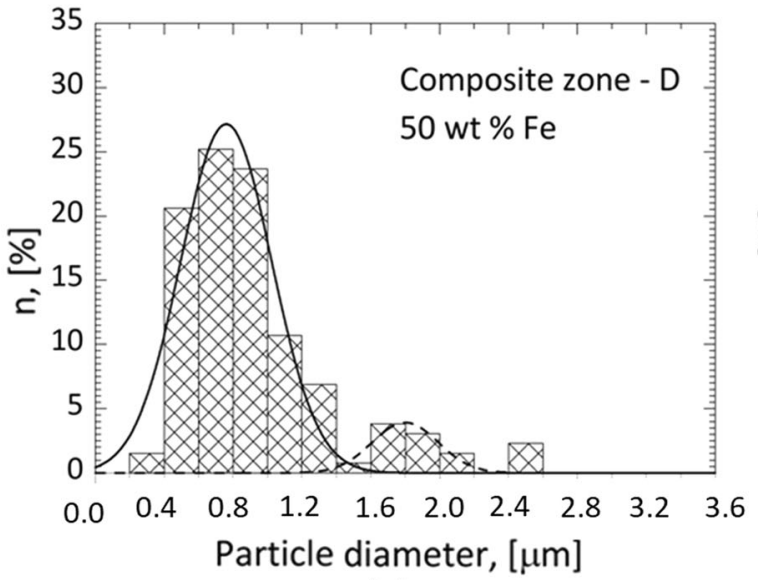

(c)

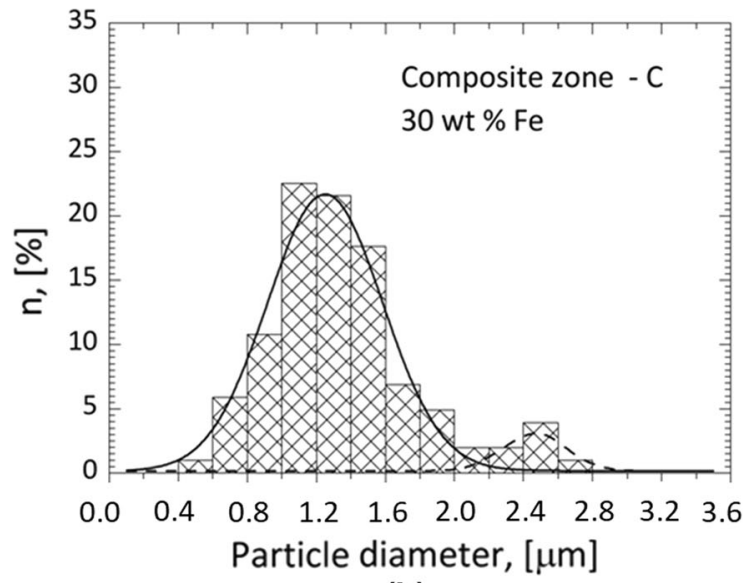

(b)

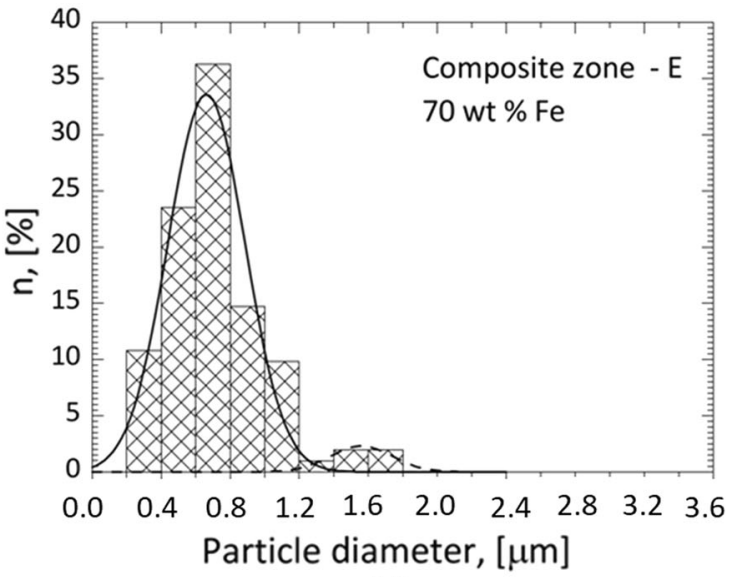

(d)

Fig. 4-Distributions of TiC particle sizes within of individual LRCs B (a), C (b), D (c), and E (d) of TiC-Fe type obtained in situ in steel casting.
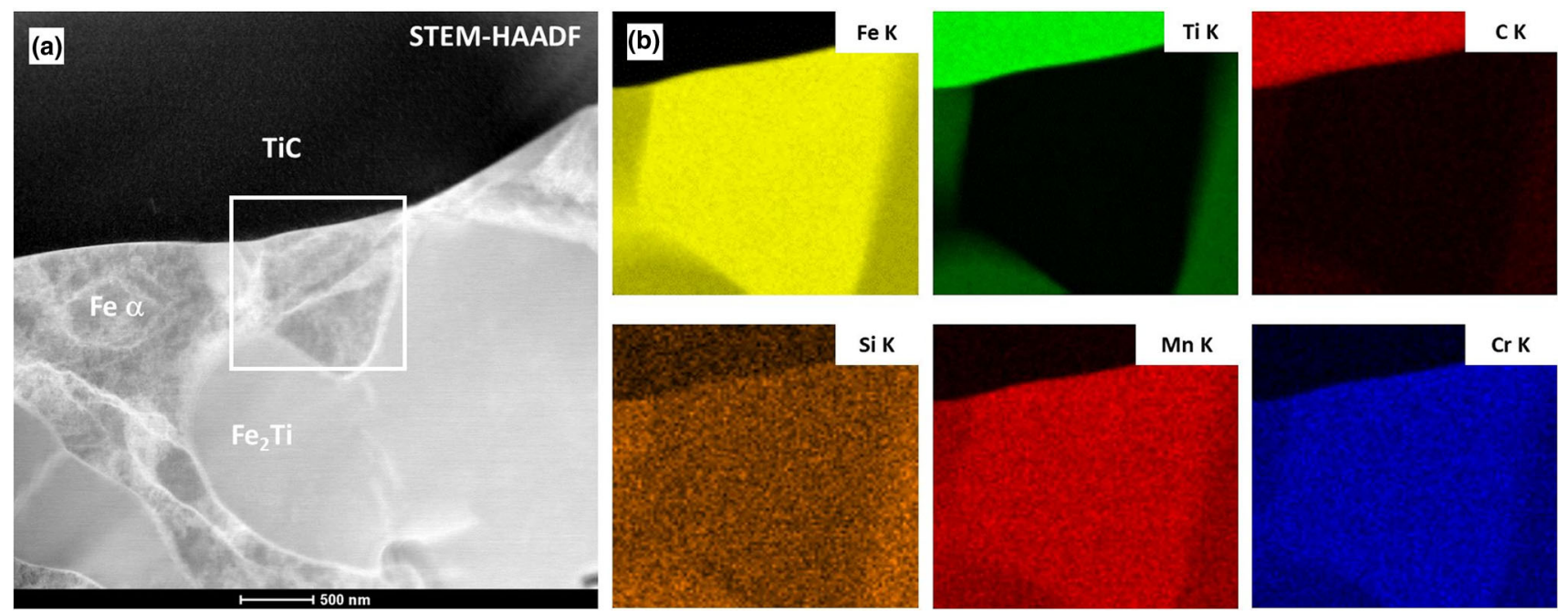

Fig. 5- (a) STEM-HAADF images taken at one magnification and (b) corresponding elemental mapping performed from indicated area showing interface between $\mathrm{TiC}$ particle and eutectic $\left(\mathrm{Fe}_{2} \mathrm{Ti}+\mathrm{Fe} \alpha\right)$ matrix of composite.

there are a statistically large number of preferential placement regions for their stable connection. As a consequence (taking into account the influence of the thermodynamic and kinetic factors discussed above), the number of nuclei is relatively small; however, the TiC particles can grow quickly. The connection of two 

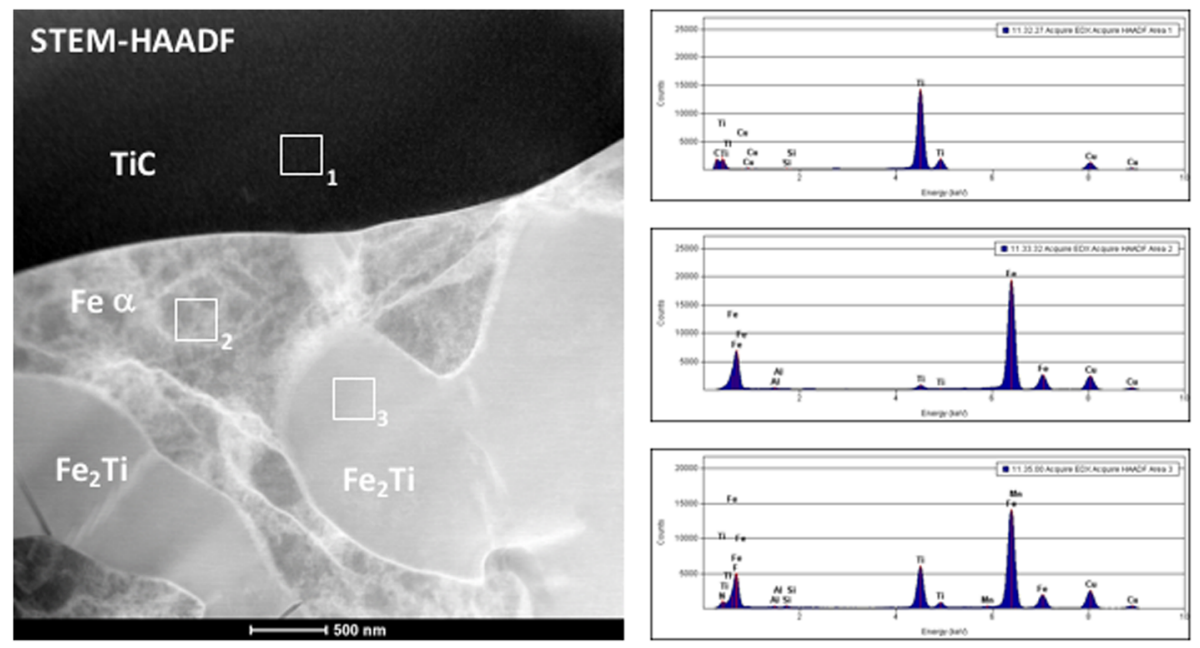

\begin{tabular}{|lcc|}
\hline Element & Weight $\%$ & Atomic $\%$ \\
$\mathrm{C}(\mathrm{K})$ & 17.83 & 46.38 \\
$\mathrm{Si}(\mathrm{K})$ & 0.06 & 0.07 \\
$\mathrm{Ti}(\mathrm{K})$ & 81.78 & 53.35 \\
$\mathrm{Cr}(\mathrm{K})$ & 0.15 & 0.09 \\
$\mathrm{Mn}(\mathrm{K})$ & 0.01 & 0.00 \\
$\mathrm{Fe}(\mathrm{K})$ & 0.15 & 0.08 \\
\hline & & \\
\hline Element & Weight $\%$ & Atomic $\%$ \\
$\mathrm{C}(\mathrm{K})$ & 0.00 & 0.00 \\
$\mathrm{Si}(\mathrm{K})$ & 0.98 & 1.92 \\
$\mathrm{Ti}(\mathrm{K})$ & 5.98 & 6.83 \\
$\mathrm{Cr}(\mathrm{K})$ & 1.79 & 1.89 \\
$\mathrm{Mn}(\mathrm{K})$ & 0.00 & 0.00 \\
$\mathrm{Fe}(\mathrm{K})$ & 91.22 & 89.34 \\
\hline & & \\
\hline $\mathrm{Element}$ & Weight $\%$ & Atomic $\%$ \\
$\mathrm{C}(\mathrm{K})$ & 0.00 & 0.00 \\
$\mathrm{Si}(\mathrm{K})$ & 0.08 & 0.15 \\
$\mathrm{Ti}(\mathrm{K})$ & 29.85 & 33.13 \\
$\mathrm{Cr}(\mathrm{K})$ & 0.12 & 0.12 \\
$\mathrm{Mn}(\mathrm{K})$ & 1.03 & 0.99 \\
$\mathrm{Fe}(\mathrm{K})$ & 68.90 & 65.58 \\
\hline
\end{tabular}

Fig. 6-STEM-HAADF image and results of chemical analysis (EDX) performed at indicated areas corresponding to different phases existing in composite.
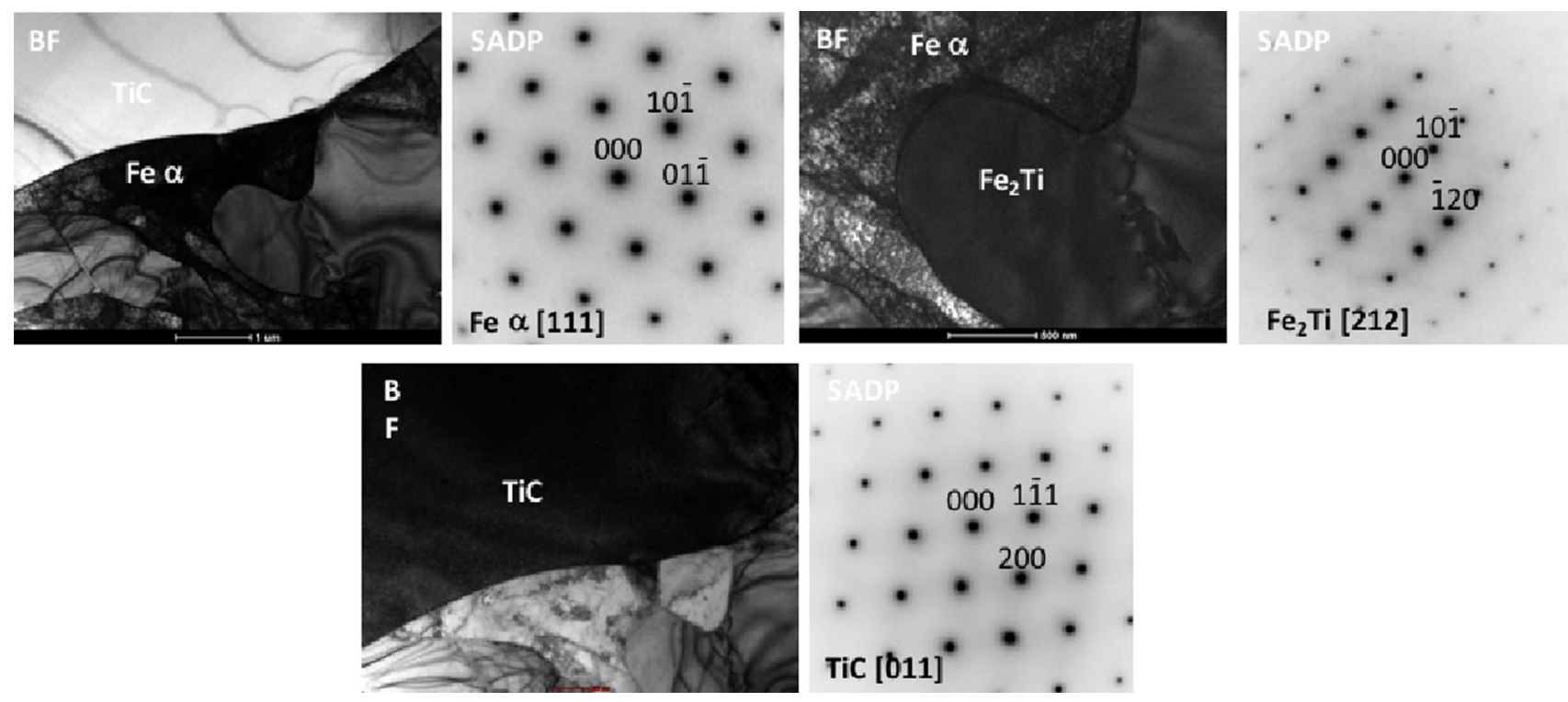

Fig. 7-BF images and corresponding selected area diffraction patterns (SADPs) showing three different phases located in composite.

different-sized $\mathrm{TiC}$ particles results in the growth of the larger one at the expense of the smaller one. ${ }^{[30]}$ In the discussed case, the increased liquid alloy temperature had a dominating influence on the coalescence phenomenon due to the highly exothermic TiC synthesis reaction. Together with the decrease in the fraction of TiC synthesis reactants (LRC B), a smaller thermal energy was dissipated, which relatively limited the coalescence; however, under such conditions, the possibility of forming a larger number of $\mathrm{TiC}$ nuclei is still limited. A further decrease in the reactants' fraction lead to such a decrease in the thermal energy accompanying the in situ $\mathrm{TiC}$ synthesis reaction that it was possible to significantly increase the number of $\mathrm{TiC}$ nuclei. The addition of the $\mathrm{Fe}$ moderator decreases the temperature in the TiC reaction area. ${ }^{[20]}$ This lead to the formation of large numbers of $\mathrm{TiC}$ particles with relatively small dimensions. This is confirmed by the microstructures of LRCs C, D, and E produced with the 30, 50, and 70 wt pct additions of the Fe moderator, respectively (see Figures 3(c) through (e)). The particle growth processes in these zones is gradually limited by the lowering temperature caused by increasing moderator amounts. The nucleation rate of $\mathrm{TiC}$ increases significantly with an increase in supercooling yet decreases again at low temperatures due to the decreasing atomic mobility described by the diffusion coefficient. ${ }^{[37,38]}$

Together with the decreasing amounts of the $\mathrm{TiC}$ reactants in individual LRCs $\mathrm{A}, \mathrm{B}, \mathrm{C}, \mathrm{D}$, and $\mathrm{E}$, the TiC volume fractions should decrease, respectively. However, due to the reactive infiltration process, Zones A and $\mathrm{B}$ increase their dimensions (Table V) and, as a consequence, the carbides formed in the reaction are distributed in a larger volume. Finally, the efficient TiC 
surface fraction in LRCs A and B is lower than in LRCs $\mathrm{C}$ and $\mathrm{D}$ (in which the infiltration was reduced by the moderator addition-Figure 5). Together with an increase in the Fe addition, the tendency of stabilizing the composite zone dimensions is seen (see Figure 2). Therefore, the surface fractions of $\mathrm{TiC}$ in Composite Zones $\mathrm{C}$ and $\mathrm{D}$ containing only 70 and 50 wt pet $\mathrm{TiC}$ reactants, respectively, are higher than those in LRCs A and B fabricated using 100 and 90 wt pct, respectively. This was confirmed by the results presented as surface fractions of $\mathrm{TiC}$ in the individual composite zones, as shown in Figure 8.

The microstructure of Composite Zone F presented in Figure 9 was significantly altered with changes to the amount of the introduced Fe moderator. The obtained zone was characterized by a smooth change from a small number of large and coagulated $\mathrm{TiC}$ particles to a large number of small and uniformly distributed particles. The gas porosity fraction is visible, growing with the amount of the introduced $\mathrm{Fe}$ moderator (see inset in Figure 9(e)). The macro- and microstructure of the graded LRC confirmed the general mechanisms discussed in the case of individual Zones A, B, C, D, and E.

\section{Phase Analysis of LRC}

The results of the phase analysis of LRCs A, B, C, D, and $\mathrm{E}$ produced in situ in steel casting are shown in Figure 10. All composite zones contain $\mathrm{TiC}$ of the face center cubic (fcc) regular structure and Fe of the body center cubic (bcc) regular structure. The presence of Fe within Zone A (produced without the $\mathrm{Fe}$ moderator addition) is the effect of the reactive infiltration process realized after pouring the melt into the mold as well as the initiation of the $\mathrm{TiC}$ synthesis. Along with an increase in the moderator contents, the infiltration process is limited. This leads to a gradual decrease in the $\mathrm{Fe}$ fraction in each of the individual zones as an effect of infiltration. Simultaneously, along with increases in the moderator content, the $\mathrm{Fe}$ fraction grows in Zones B, C, D, and E, respectively. This is well illustrated by the change in the intensity of reflexes from

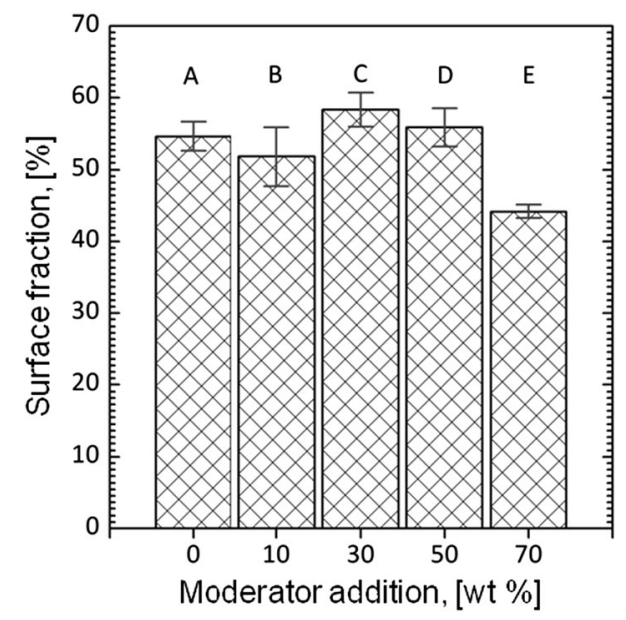

Fig. 8-Surface fractions of TiC within individual LRCs A, B, C, D, and $\mathrm{E}$ of TiC-Fe type obtained in situ in steel casting. the (110) Fe planes. The intensity of reflexes originating from the TiC crystal lattice gradually decreases for Zones B, D, and $\mathrm{E}$ along with the decreasing contents of the $\mathrm{TiC}$ substrates in the initial powder composition. This is illustrated by the reflexes from the TiC planes, for example (200). In the case of Zone $C$, a relative intensity increase as compared to the B, D, and $\mathrm{E}$ zones can be seen. This is the effect of the highest area fraction (see Figure 4) and the large number of small $\mathrm{TiC}$ particles (see Figure 3(c)), which results in the highest number of planes scattering the $\mathrm{X}$-ray radiation.

\section{Hardness of $L R C$}

Composite Zone A (produced without the Fe moderator) has the relatively highest hardness - an average of 500 HV30 (Figure 11). The hardness confidence interval for a deviation of $2 \sigma$ is wide, which confirms the microstructure heterogeneity being the result of the occurrence of relatively large areas of coagulates of the $\mathrm{TiC}$ particles and matrix lakes (see Figure 3(a)). This zone hardness is determined by the large coagulation degree of the carbides, forming a strong skeleton and soft matrix area. Composite Zone B (obtained with a 10 wt pet Fe addition) has a hardness of 350 HV30 (lower than that of Zone A). The high degree of infiltration decreasing the efficient TiC fraction (see Figure 5) in the microarea continues to have a significant influence on the hardness of Zone B. On account of the solidification process and smaller fraction of the $\mathrm{TiC}$ reaction substrates, the particles in Zone B are less coagulated (see Figure 3(b)) and form a weaker skeleton than those in Zone A (which causes a relative hardness decrease). The tendency of decreasing hardness observed in Zone B is reversed in the case of Zones $\mathrm{C}$ and $\mathrm{D}$ (produced with additions of 30 and 50 wt pet of the moderator, respectively), in which the average hardness equals 400 and $380 \mathrm{HV} 30$, respectively. The hardness values of Zones $\mathrm{C}$ and $\mathrm{D}$ are formed by the low infiltration degree realized by the base alloy (see Figure 2) and the $\mathrm{TiC}$ particles of high dispersion uniformly distributed throughout the matrix (see Figures 3(c) through (e)). By the high surface fraction (see Figure 5) and refinement of the TiC particles, the contact between them is facilitated by the many touching grains, ensuring skeleton stiffness. A high TiC surface fraction influencing the connectivity and related with its coordination number of $\mathrm{TiC}$ particles ${ }^{[39]}$ and maximum hardness is observed for LRC C (see Figure 8). In the case of Composite Zone E, a decrease in hardness is seen. This results from the smallest surface fraction, lower coordination number, and (as a consequence) more-weakly joined TiC particles (see Figure 3(e)). Also, the large fractions of the $\mathrm{Fe}$ moderator and porosity have a negative impact on the hardness of Zone E.

Figure 12 presents the hardness distribution within graded composite reinforcement $F$. This distribution confirms the general trend of hardness changes depending on the amount of the moderator observed in individual LRCs A, B, C, D, and E (see Figure 8). The hardness of the graded composite zone results from the microstructure features of its individual layers. 

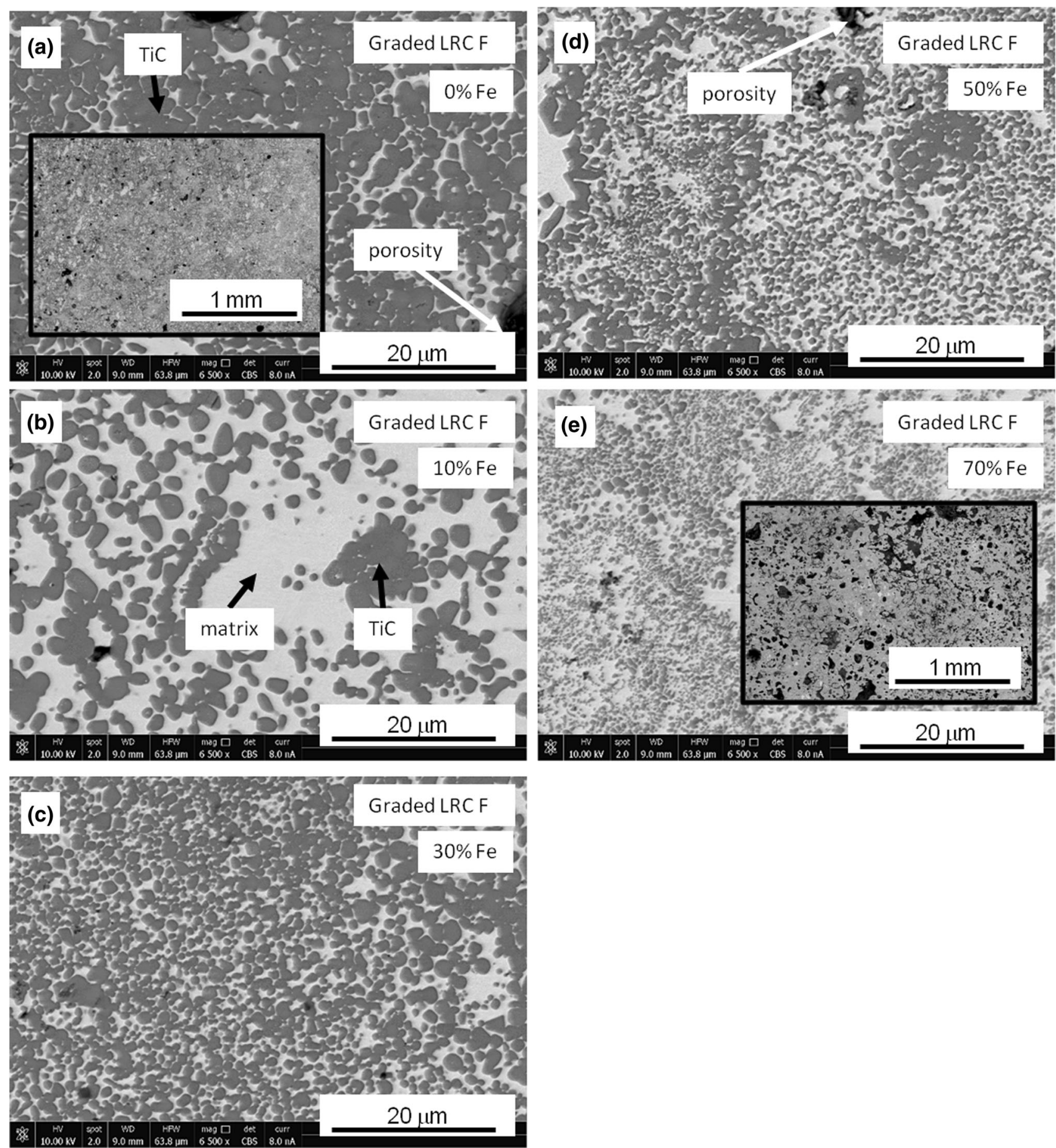

Fig. 9-SEM BSE microstructures of graded F LRC of TiC-Fe type obtained in situ in steel casting (a) 0 pet Fe, (b) 10 pct Fe, (c) 30 pet Fe, (d) 50 pet Fe, and (e) 70 pet Fe.

Additionally, the hardness is decreased in the area layer fabricated with a $70 \mathrm{wt}$ pct moderator by the microporosity (see inset in Figure 6(e)).

\section{SUMMARY}

The mechanism of the in situ formation of LRC in steel castings was investigated in this paper. It was tested by introducing compacts into a mold cavity containing either reactants of the $\mathrm{TiC}$, and these reactants together with additions of 10,30, 50, and $70 \mathrm{wt}$ pct of the Fe moderator. It was found that, when the compacts contained only the reactants of the TiC formation, an LRC with macroscopic discontinuities, dimensional changes, and partial fragmentation was obtained. Introducing a moderator in the form of $\mathrm{Fe}$ powder into the $\mathrm{TiC}$ reactants influences the dimensional stability of the LRC and eliminates the 


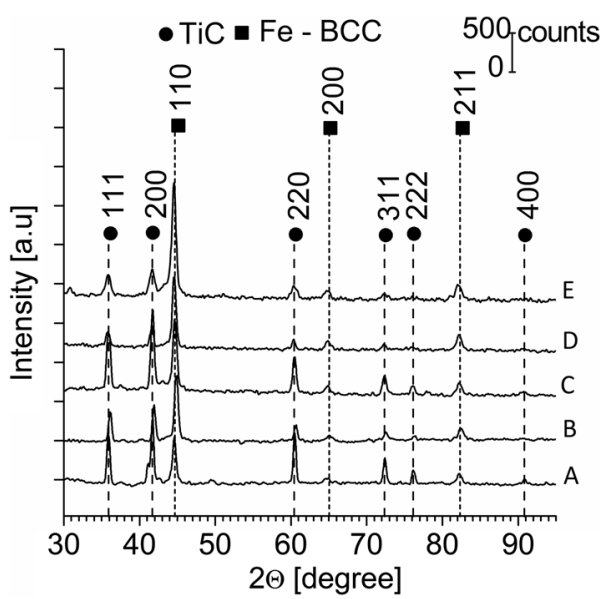

Fig. 10-X-ray diffraction patterns of individual LRCs A, B, C, D, and $\mathrm{E}$ of TiC-Fe type obtained in situ in steel casting.

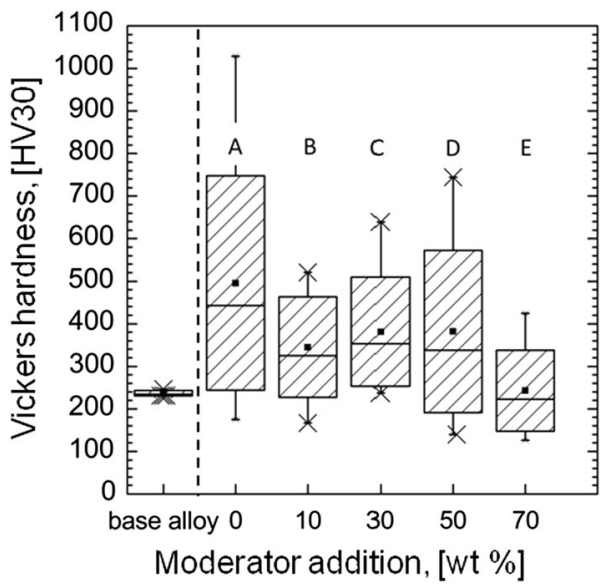

Fig. 11-Vickers hardness values of individual LRCs A, B, C, D, and $\mathrm{E}$ of TiC-Fe type obtained in situ in steel casting.

macro-discontinuities within them. This results from limiting the amount of the TiC-forming reactants and substituting them partially by adding the moderator. As a consequence, this leads to decreased energy in the reaction area, which permits us to control the reactive infiltration, gas solving, and emission processes. Adding the moderator makes it possible to control the amount of energy and the solidification process, including the nucleation and TiC particle growth. For the determined amount of moderator, it is possible to obtain composite zones with TiC particles of submicronic sizes. The hardness of the LRC obtained in situ in the steel castings is influenced by the infiltration degree and (as a consequence) the surface fraction of the TiC particles. Along with an increase in the surface fraction of the $\mathrm{TiC}$ particles within the zone, hardness also increases. This is influenced by the number of connections between the particles and their surface fraction. When LRCs are synthesized in situ in castings, then their hardness is not the highest when the contents of the $\mathrm{TiC}$ reactants in the initial powder composition are the largest (as to be expected). The intensive reactive infiltration process causes a decrease in the particle surface fraction in the LRC microarea by increasing its

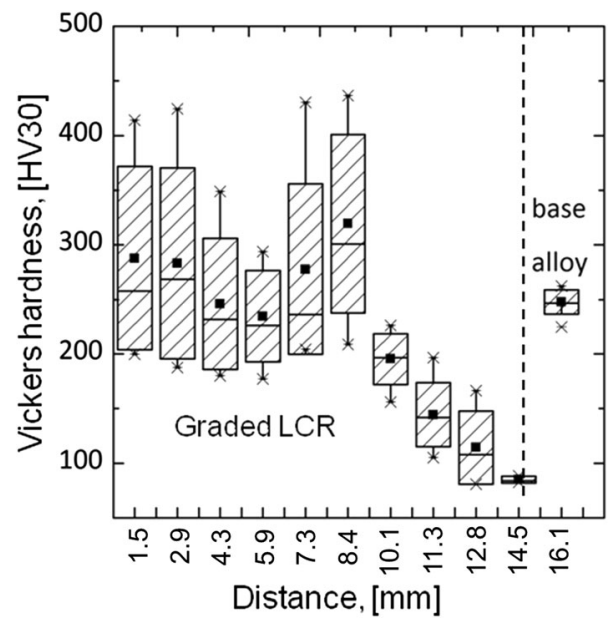

Fig. 12-Distribution of Vickers hardness within graded LRC F of TiC-Fe type obtained in situ in steel casting.

dimensions. The highest zone hardness is obtained when the infiltration is limited. In the discussed case, the infiltration was limited by the moderator addition, which simultaneously provided a refinement of the TiC particles. Finally, the chemical composition of the initial powders was determined, the use of which guarantees that we obtain a dimensionally stable LRC with relatively uniformly distributed $\mathrm{TiC}$ particles of submicronic sizes in the steel casting under the described experimental conditions.

\section{ACKNOWLEDGMENT}

This study was supported by the Polish National Science Center (NCN-Project No. NN507311040).

\section{OPEN ACCESS}

This article is distributed under the terms of the Creative Commons Attribution 4.0 International License (http://creativecommons.org/licenses/by/4.0/), which permits unrestricted use, distribution, and reproduction in any medium, provided you give appropriate credit to the original author(s) and the source, provide a link to the Creative Commons license, and indicate if changes were made.

\section{REFERENCES}

1. J.J. Moore and H.J. Feng: Prog. Mater. Sci., 1995, vol. 39, pp. 243-73.

2. J.J. Moore and H.J. Feng: Prog. Mater. Sci., 1995, vol. 39, pp. 275-316.

3. A.G. Merzhanov: J. Mater. Process. Technol., 1996, vol. 56, pp. $222-41$.

4. E. Fraś, A. Janas, P. Kurtyka, and S. Wierzbiński: Arch. Metall. Mater., 2004, vol. 49, pp. 113-41.

5. F. Ye, M. Hojamberdiev, Y. Xu, L. Zhong, N. Zhao, Y. Li, and X. Huang: Appl. Surf. Sci., 2013, vol. 280, pp. 297-303. 
6. L. Niu, Y. Xu, and X. Wang: Surf. Coat. Technol., 2010, vol. 205, pp. $551-56$.

7. L. Niu, M. Hojamberdiev, and Y. Xu: J. Mater. Process. Technol., 2010, vol. 210, pp. 1986-90.

8. L. Zhong, X. Zhang, S. Chen, Y. Xu, H. Wu, and J. Wang: Int. J. Refract. Metals Hard Mater., 2016, vol. 57, pp. 42-49.

9. Y. Wang, F. Li, G. Zeng, and D. Feng: Mater. Des., 1999, vol. 20, pp. 19-22.

10. Y. Wang, X. Zhang, G. Zeng, and F. Li: Compos. Part A, 2001, vol. 32, pp. 281-86.

11. H.Y. Wang, Q.C. Jiang, B.X. Ma, Y. Wang, and F. Zhao: J Alloys Compd., 2005, vol. 39, pp. 55-59.

12. Q.C. Jiang, F. Zhao, H.Y. Wang, and Z.Q. Zhang: Mater. Lett., 2005, vol. 59, pp. 2043-47.

13. H.Y. Wang, L. Huang, and Q.C. Jiang: Mater. Sci. Eng. A, 2005, vol. 407 , pp. $98-104$.

14. Q.C. Jiang, B.X. Ma, H.Y. Wang, Y. Wang, and Y.P. Dong: Compos. Part A Appl. Sci. Manuf., 2006, vol. 37, pp. 133-38.

15. Y. Wang, Z.Q. Zhang, H.Y. Wang, B.X. Ma, and Q.C. Jiang: Mater. Sci. Eng. A, 2006, vol. 422, pp. 339-45.

16. Y.F. Yang, H.Y. Wang, Y.H. Liang, R.Y. Zhao, and Q.C. Jiang: Mater. Sci. Eng. A, 2007, vols. 445-446, pp. 398-404.

17. Y.F. Yang, H.Y. Wang, Y.H. Liang, R.Y. Zhao, and Q.C. Jiang: Mater. Sci. Eng. A, 2008, vol. 474, pp. 355-62.

18. M.S. Song, M.X. Zhang, S.G. Zhang, B. Huang, and J.G. Li: Mater. Sci. Eng. A, 2008, vol. 473, pp. 166-71.

19. B. Zou, P. Shen, X. Cao, and Q. Jiang: Mater. Chem. Phys., 2012, vol. 132, pp. 51-62.

20. Y. Liang, Z. Han, Z. Zhang, X. Li, and L. Ren: Mater. Des., 2012, vol. 40, pp. 64-69.

21. Y. Liang, Q. Zhao, Z. Zhang, X. Li, and L. Ren: J. Asian Ceram. Soc., 2014, vol. 2, pp. 281-88.

22. S.W. Hu, Y.G. Zhao, Z. Wang, Y.G. Li, and Q.C. Jiang: Mater. Des., 2013, vol. 44, pp. 340-45.
23. E. Olejnik, M. Górny, T. Tokarski, B. Grabowska, A. Kmita, and G. Sikora: Arch. Metall. Mater., 2013, vol. 58, pp. 465-71.

24. E. Olejnik, G. Sikora, S. Sobula, T. Tokarski, and B. Grabowska: Mater. Sci. Forum, 2014, vol. 782, pp. 527-32.

25. W. Zhang, X. Zhang, J. Wang, and Ch. Hong: Mater. Sci., 2004, vol. 381, pp. 92-97.

26. J. Zhang, J.M. Lee, Y.H. Cho, S.H. Kim, and H. Yu: Scr. Mater., 2013 , vol. 69 , pp. $45-48$.

27. Y. Tong, S. Bai, X. Liang, Q.H. Qin, and J. Zhai: Ceram. Int., 2016, vol. 42, pp. 17174-78.

28. Y. Tong, S. Bai, Y. Ye, H. Zhang, and Z. Yang: Mater. Lett., 2015, vol. 138 , pp. 208-11.

29. Q. Dong, L.Q. Chen, M.J. Zhao, and J. Bi: Mater. Lett., 2004, vol. 58 , pp. 920-26.

30. E. Olejnik and A. Jesiolowska: International application No PCT/ IB2016/056825, Powder composition for the manufacture of casting inserts, casting insert and method of obtaining local composite zones in castings.

31. A.S. Shchukin and S.G. Vadchenko: Int. J. Self-Propag. HighTemp. Synth., 2015, vol. 24, pp. 227-30.

32. R.M. German, P. Suri, and S.J. Park: J. Mater. Sci., 2009, vol. 44, pp. 1-39.

33. H. Ohtani, T. Tanka, M. Hasebe, and T. Nishizawa: Calphad, 1988, vol. 12 (3), pp. 225-46.

34. R.M. German and Z.A. Munir: Metall. Trans. A, 1975, vol. 6, pp. 2229-34.

35. E. Einstein: Ann. Phys., 1905, vol. 17, pp. 549-60.

36. Y. Min, M. Akbulut, K. Kristiansen, Y. Golan, and J. Israelachvili: Nat. Mater., 2008, vol. 7, pp. 527-38.

37. D. Turnbull and J.C. Fisher: J. Chem. Phys., 1949, vol. 17, pp. 71-73.

38. A.L. Greer and K.F. Kelton: J. Am. Ceram. Soc., 1991, vol. 74, pp. 1015-22.

39. R.M. German: Powder Technol., 2014, vol. 253, pp. 368-76. 